\title{
MATHEMATICAL MODELING AND PERFORMANCE EVALUATION FOR A SOLAR WATER PUMPING SYSTEM IN EGYPT
}

\author{
Said M. A. Ibrahim ${ }^{1}$, H. H. El-Ghetany ${ }^{2}$ and A. G. M. Shabak ${ }^{1}$ \\ ${ }^{1}$ Mechanical Engineering Department, Al-Azhar University, Cairo, Egypt \\ ${ }^{2}$ Solar Energy Department, National Research Centre, Dokki, 12622, Giza, Egypt.
}

\begin{abstract}
Solar water pumping systems are the ideal energy provider solution especially in rural and isolated areas where the traditional sources of power (electricity or diesel) are unavailable or very costly. It is available with abundant quantities of daily falling solar radiation of about 5.5 $\mathrm{kWh} / \mathrm{m}^{2} /$ day and considered a clean source of energy. The present work provides a mathematical model and performance evaluation of a solar water pumping system for different water demands through a comprehensive design tool simulation program prepared and designed by the authors. The simulated results can provide for the studied water demand range, the corresponding pump electric power for the desired total dynamic head, the required PV peak power, its related area requirements, and the corresponding total cost of the system components in Euro. The present research is a good accurate quick tool for designers, users, and buyers of such systems.
\end{abstract}

\section{Keywords: Mathematical model, solar, water pumping system, water demand, Efficiency, PV sizing.}

\section{INTRODUCTION}

To overcome the present gap between water demands in the agriculture sector nowadays, Solar Water Pumping Systems (SWPS) are considered as the essential and crucial solution to provide the required energy for this demands. A SWPS can be a cost effective, stand-alone for serving the remote watering needs, whether it is for irrigation, animal grazing, or potable use. The need of solar pumps in Egypt is an extremely important topic that depends on the availability of solar radiation and the amount of stored underground water. The availability of underground water in the Egyptian desert is given by the National Specialized Boards [1]. Solar radiation is abundantly available since Egypt is lying in the middle of the solar belt countries with an average value of $5.5 \mathrm{kWh} / \mathrm{m}^{2} /$ day. Solar energy as an inexhaustible, renewable and clean source of energy can effectively reduce high pollutions, global warming, and climatic changes. SWPS has low operating costs in general that gives it the advantage of being cost-effective systems. The irrigation water withdrawal is the sum of the actual water needed for irrigation, with the addition of the water that is lost in its distribution and application, which by far exceeds the consumptive use of irrigation [2]. 
Much research effort has been conducted to minimize the losses of irrigation water. Drip irrigation is the method that presents the lowest water losses and consequently needs the least amount of water in order to sufficiently irrigate a plantation [3]. ost photovoltaic (PV) pumping systems nowadays are equipped with a Maximum Power Point Tracker (MPPT). This electronic device is a DC-DC converter that is able to operate the PV array in its maximum power point for any given solar irradiation [4]. A benefit of using solar energy to power agricultural water pump systems is that the increased water requirements for livestock and irrigation tend to coincide with the seasonal increase of incoming solar energy.

This means that the volume of water pumped by the SWPS in a given interval depends on the total amount of solar energy available in that time period. Specifically, the flow rate of the water pumped is determined by both the intensity of the solar energy available and the size of the PV array used to convert that solar energy into direct current (DC) electricity. The principle components of the SWPS are PV array and its supporting structure, an electrical controller, and an electric-powered pump [5]. It is important that the components be designed as part of an integrated system to ensure that all the equipment are compatible and that the system operates as intended. Solar-powered pumps are characterized as either positive displacement pumps (e.g.,

diaphragm, piston, or helical rotor) or centrifugal pumps. The scope of this research paper is to present a mathematical model and develop a simulation program to evaluate the system performance of the SWPS for different flow rates and TDH. Finally, a complete sizing of the system components is identified; the system cost, power, and land requirements are estimated.

\section{MATHEMATICAL MODELING}

In order to present the complete design process of the SWPS, some basic information should be known as follows:

1. The amount of solar energy falling on the horizontal surface.

2. The water demand.

3. The Total Dynamic Head (TDH).

4. Selecting a pump that will cover the water demand and the desired pressure.

5. Sizing the PV capacity $(\mathrm{kW})$ to power the required pump electric load.

6. Estimating the system land requirements.

7. Estimating the SWPS cost.

A simulation program is constructed based on the mathematical modeling of the system components and as per the algorithm shown in the flow chart presented in Fig.1. This program is fed with the necessary input data, and the output provides all the designed results. The program is even capable of giving the recommended companies that can supply all equipment. The program is versatile and can give different solutions to choose from based on the input data and costumer requirements and budget. This program serves as a solar energy recipe.

\section{Calculation of the water demand}

Calculating the water demand depends on a lot of different factors like user identity (human, kind of animal, kind of plant), climate conditions for a given site, environment, kind of irrigation, lifestyle for humans, and activity (cooking, drinking, bathing, ...etc). The average water consumption for different activities per person and per a certain kind of animal is determined based on the Egyptian standard code as follows [9] 


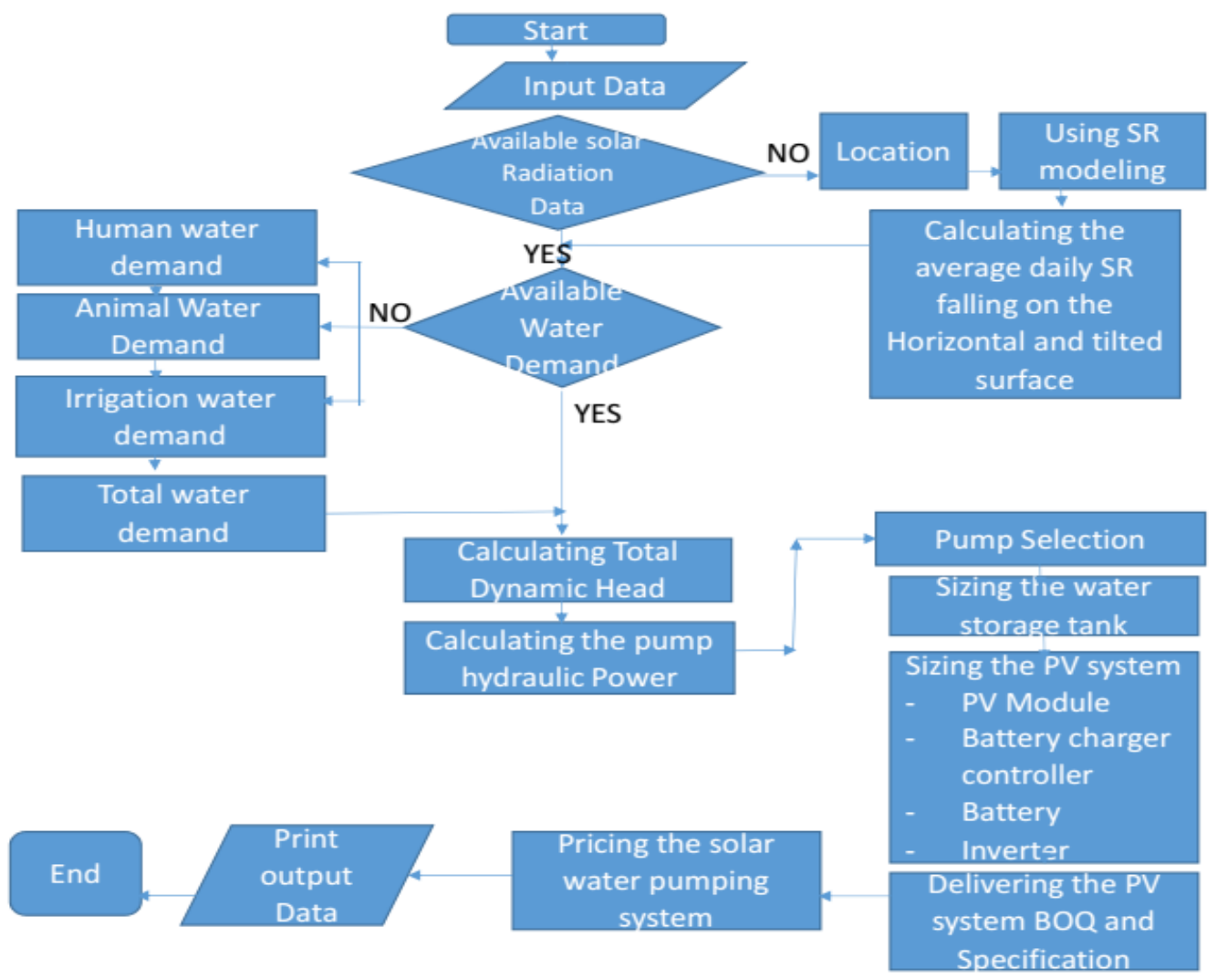

Fig. 1 Flow chart of the present simulation model.

$Q=Q_{H C}+Q_{A C}+Q_{A G C}+Q_{O C}$

Where

$\mathrm{Q}=$ Total water demand per day $\left(\mathrm{m}^{3} /\right.$ day $)$,

$Q_{H C}=$ Daily water demand for Human Consumption, $\left(\mathrm{m}^{3} /\right.$ day $)$,

$Q_{A C}=$ Daily water demand for Animal Consumption, $\left(\mathrm{m}^{3} /\right.$ day $)$,

$Q_{A C}=$ Daily water demand for Agriculture Consumption, $\left(\mathrm{m}^{3} /\right.$ day $)$, and

$Q_{o c}=$ Other Consumption, $\left(\mathrm{m}^{3} /\right.$ day) .

The daily water demand based on the previously mentioned parameters are calculated as per the simulation program worksheet shown in Fig. 2.

\section{Calculating the total dynamic head}

The Total Dynamic Head (TDH) is the sum of the total static head $\left(h_{s}\right)$, the friction head losses $\left(h_{\mathrm{f}}\right)$ and the minor head losses $\left(\mathrm{h}_{\mathrm{m}}\right)$. The total static head is the height difference between the water source inlet $\left(Z_{1}\right)$ and the level of water outlet $\left(Z_{2}\right)$. The friction head losses $\left(\mathrm{h}_{\mathrm{f}}\right)$ in the system are due to the wall shear stress encountered at the interface between the fluid in the pipes and the pipe walls. It is directly proportional to the pipe length (L) and inversely proportional to the inner diameter of the pipe (d). Additionally the friction head losses are related to a friction factor (f), which is dependent on the Reynolds number $\left(R_{e}\right)$ of the flow and the relative roughness of the inner pipe walls $(\varepsilon)$. 


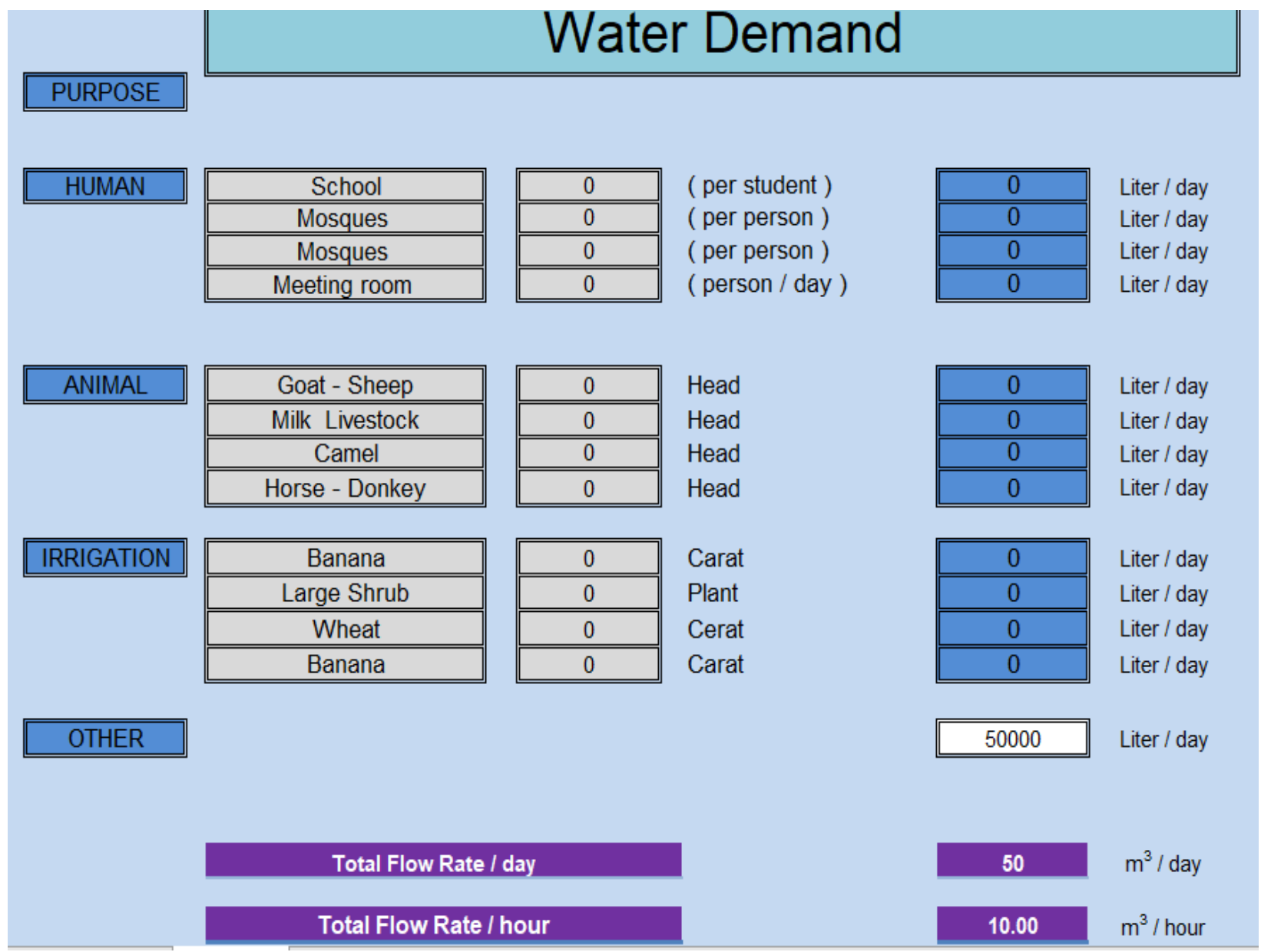

Fig. 2 simulation program worksheet for calculating the daily water demand.

The minor head losses $\left(\mathrm{h}_{\mathrm{m}}\right)$ in the system are due to the unstable turbulent flow in pipe fittings, connectors and valves. Its magnitude is quantified by a loss factor $(\mathrm{k})$, which is specific to each type of fitting and independent of the fitting material [10].

The total dynamic pumping head is represented as [11]

$$
\mathrm{TDH}=\mathrm{hs}+\mathrm{hf}+\mathrm{hm}=(\mathrm{z} 2-\mathrm{z} 1)+\frac{\mathrm{v} 2}{2 \mathrm{~g}}\left(\mathrm{f} \frac{\mathrm{l}}{\mathrm{d}}+\mathrm{z} \mathrm{k}\right)
$$

Where

$v=$ velocity of flow $(\mathrm{m} / \mathrm{s})$,

$\mathrm{f}=$ friction factor,

$\mathrm{I}=$ length of pipe $(\mathrm{m})$,

$\mathrm{d}=$ diameter of pipe $(\mathrm{m})$, and

$\mathrm{k}=$ the loss coefficient for different components.

The details of program output worksheet for calculating the total suction head are illustrated in Fig. 3. While the program output for the total dynamic head is indicated in Fig. 4. 


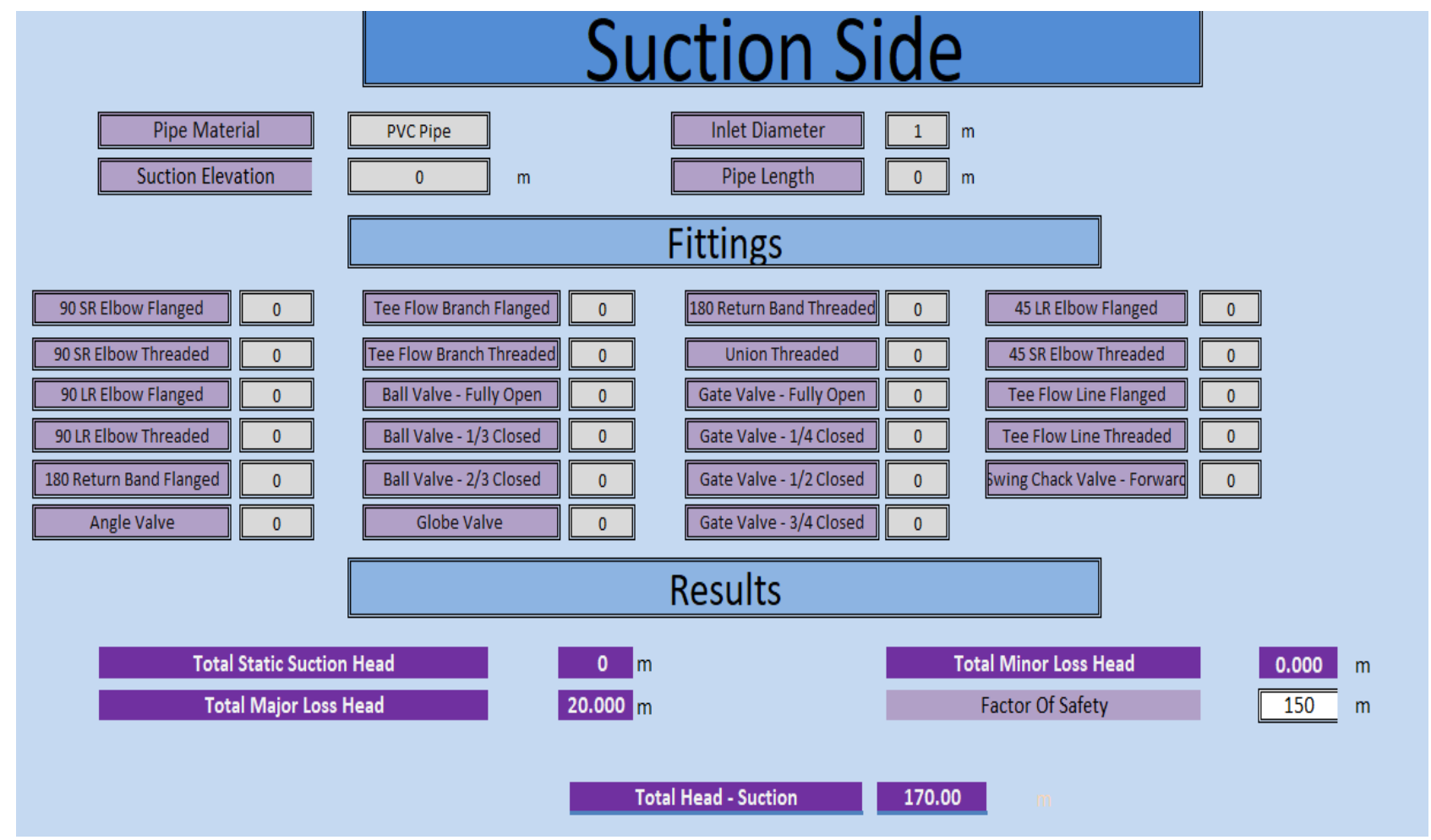

Fig. 3 Details of program output worksheet for calculating the total suction head.

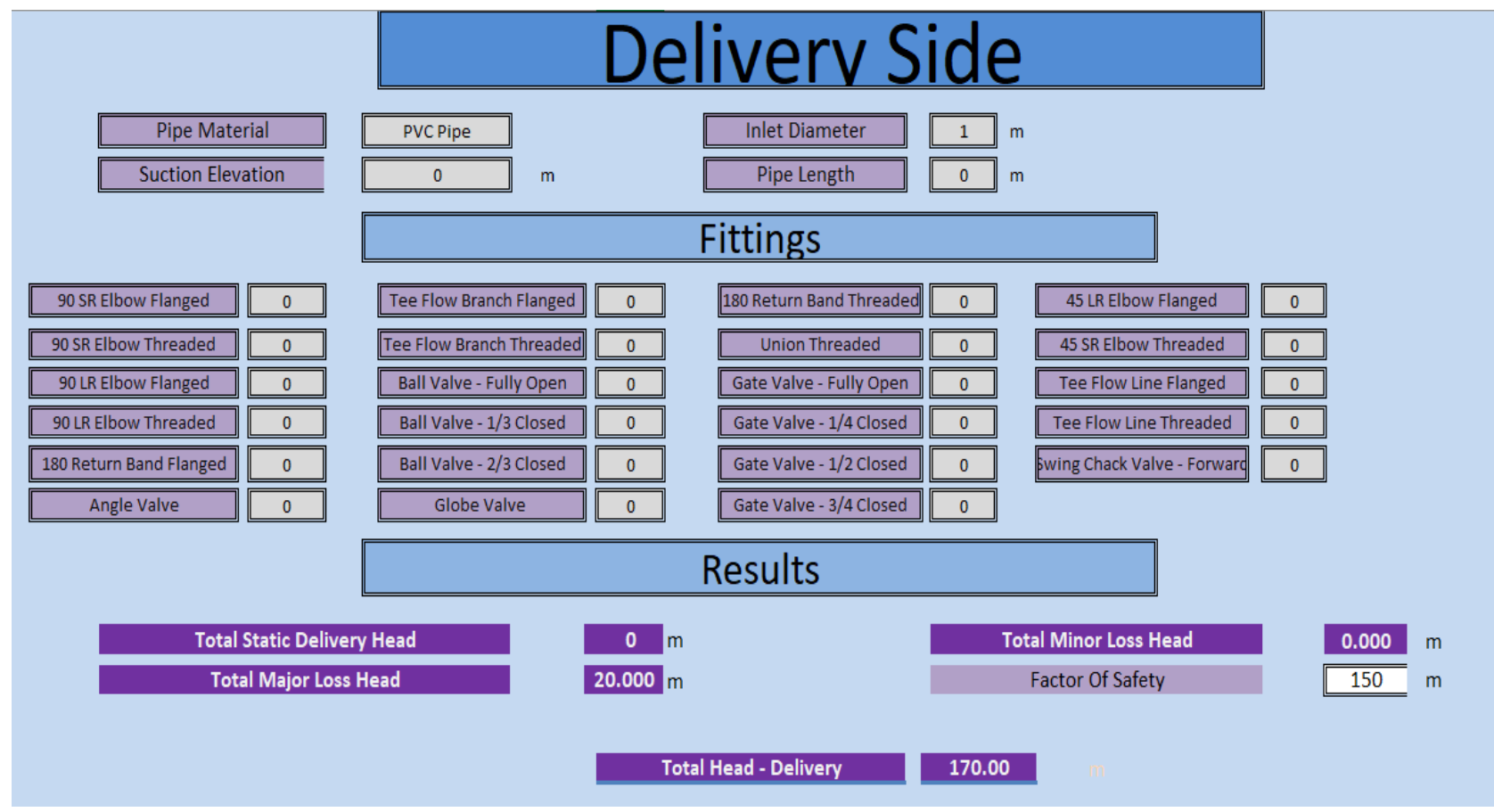

Fig. 4 Details of computer output for calculating the total dynamic head. 


\section{Pump Selection}

Pump sizing can be calculated based on these factors:

- Pump flow rate $\left(\mathrm{m}^{3} /\right.$ day).

- Pumping head $(\mathrm{m})$.

- Type of operation (centrifugal or positive displacement)

- Water source (surface or submersible).

- Different manufacturer's available manuals.

\section{Hydraulic Power}

The hydraulic Power, $\mathrm{P}_{\mathrm{h}}$, required to lift a volume of water over a total head, TDH is $\mathrm{P}_{\mathrm{h}}=\rho_{\mathrm{w}} \mathrm{gTDH}$

Where

$\rho_{\mathrm{w}}=$ Density of water $\left(1000 \mathrm{~kg} / \mathrm{m}^{3}\right)$,

$\mathrm{g}=$ Acceleration due to gravity $\left(9.81 \mathrm{~m} / \mathrm{s}^{2}\right)$, and

$\mathrm{Q}=$ Flow rate or volume of water lifted per second in $\mathrm{m}^{3} / \mathrm{s}$.

The simulation program presents a complete selection for surface and submersible pumps as depicted in Fig. 5

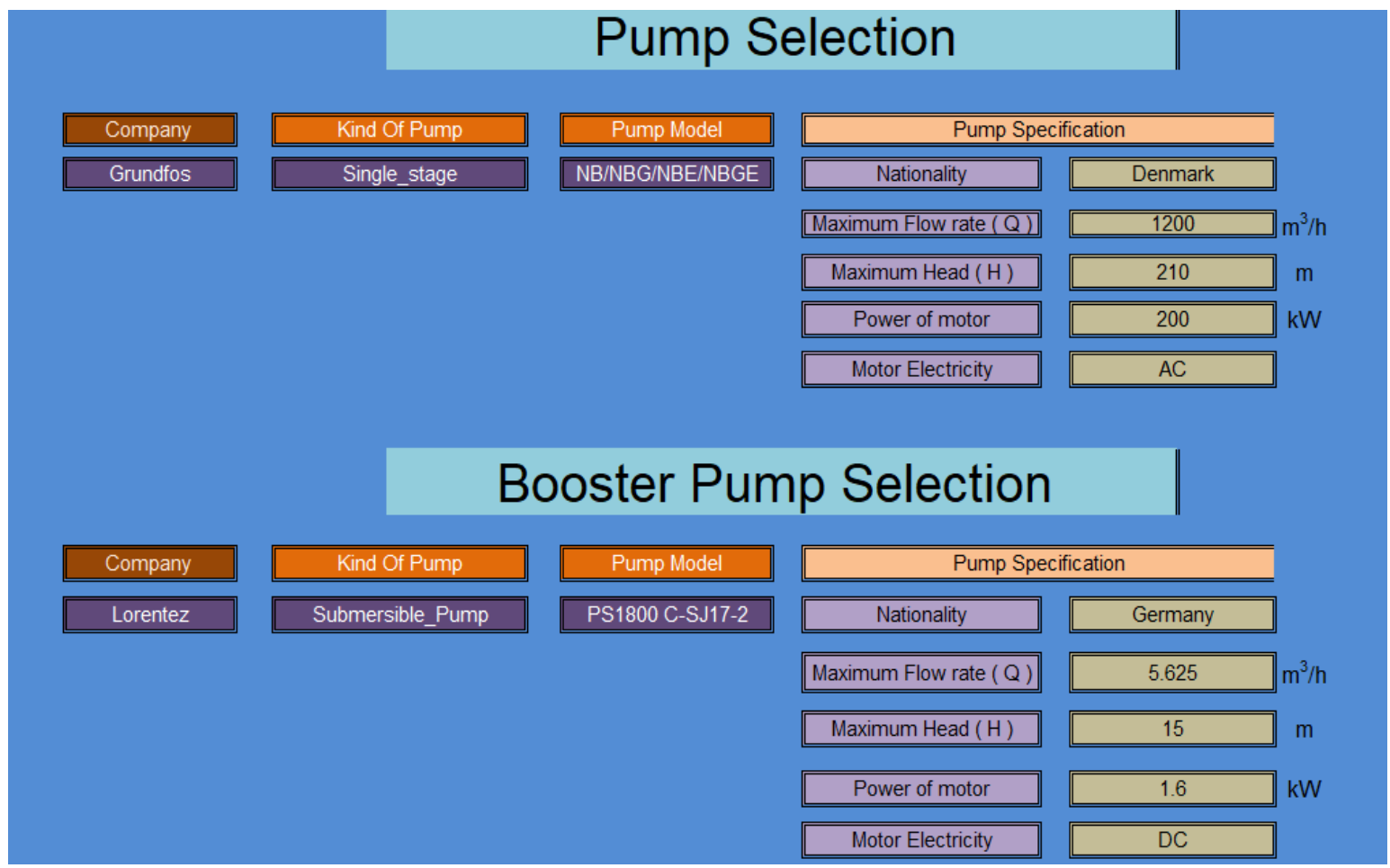

Fig. 5 Simulation program worksheet for a complete selection of surface and submersible pumps.

\section{Solar water pumping system}

It is essential to calculate the adequate power rating for a photovoltaic system to meet the total required electricity load. Before designing the system, the daily average sun hour, amount of daily solar radiation falling on the horizontal surface, and the ambient temperature should be defined. The SWPS consists of the following components [12]:

- PV module which converts solar energy into electricity to drive the pumps.

- Inverter to covert DC power generated from the PV panel to AC to meet the load of the pumps.

- Battery bank to drive the pumps shortage of solar radiation and charger controller to regulate and adapt battery charging (in case of using storage system).

- Variable speed pump to be operated according to the variable solar energy input (in case of not use storage system). 
The SWPS described above with a submersible variable speed pump is illustrated in Fig. 6.

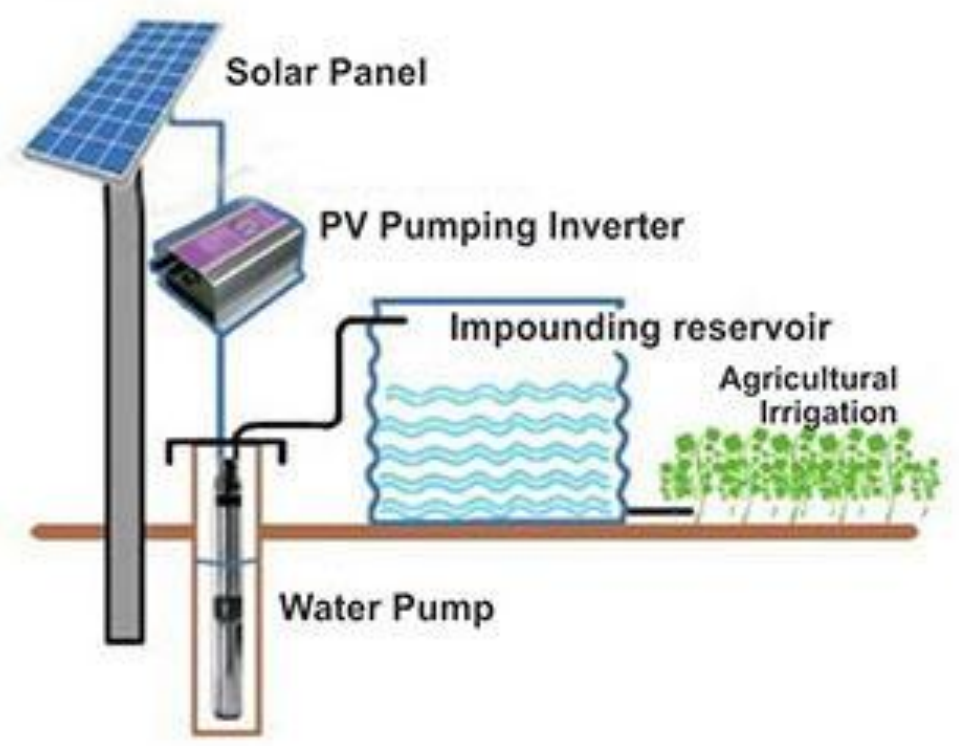

Fig.6 A typical solar-powered water pump system, which includes a solar array, controller, submersible pump, and storage tank [13].

\section{Estimating the system land requirements}

The size of the PV system in Wp for the peak load can be defined as [14]

Afv $=\frac{\text { EL }}{\mathrm{H} \times \eta_{\mathrm{pv}} \times \eta_{\text {inv }} \times \eta_{\mathrm{B}} \times \eta_{\mathrm{cc}} \times \mathrm{T}_{\mathrm{c}}}$

Where

$\mathrm{A}_{\mathrm{pv}}=$ total area of photovoltaic requirement $\left(\mathrm{m}^{2}\right)$,

$\mathrm{E}_{\mathrm{L}}=$ Peak daily required electrical energy for the SWPS (Wh/day)

$\mathrm{H}=$ daily global irradiation $\left(\mathrm{Wh} / \mathrm{m}^{2} / \mathrm{d}\right)$,

$\eta_{p v}, \eta_{i n v}, \eta_{B}, \eta_{c c}=$ efficiencies for photovoltaic, inverter, battery and charge controller, respectively, and

$\mathrm{T}_{\mathrm{c}}=$ Temperature correction factor of the PV module.

\section{Sizing the PV capacity $(\mathrm{kW})$}

The required photovoltaic modules power $\mathrm{P}_{\mathrm{pv}}(\mathrm{W})$, to meet the electric load demand can be estimated as follows

$\mathrm{P}_{\mathrm{pv}}=\mathrm{A}_{\mathrm{pV}} \times \mathrm{Hsc} \times \eta_{\mathrm{pV}}$

Where

$\mathrm{H}_{\mathrm{sc}}=$ Standard solar irradiation, $1,000 \mathrm{~W} / \mathrm{m}^{2}$.

After estimating the total area of PV panels $\left(\mathrm{m}^{2}\right)$, the number of total modules $\left(\mathrm{N}_{\mathrm{m}}\right)$ can be determined based on the commercially available area of a single PV panel. The number of modules can be defined as follows

$\mathrm{N}_{\mathrm{m}}=\frac{\mathrm{PFV}_{\mathrm{m}}}{\mathrm{P}_{\mathrm{m}}}$

Where 
$\mathrm{P}_{\mathrm{m}}$ is the power of the single module $(\mathrm{W})$.

To calculate the actual area of all modules, $A_{t}$, and exact peak power for the total modules $P_{t}$, using following equations

$$
\begin{aligned}
& \mathrm{A}_{\mathrm{t}}=\mathrm{N}_{\mathrm{m}} \times \mathrm{A}_{\mathrm{m}} \\
& \mathrm{P}_{\mathrm{t}}=\mathrm{N}_{\mathrm{m}}^{\prime} \times \mathrm{P}_{\mathrm{m}}
\end{aligned}
$$

where

$\mathrm{A}_{\mathrm{m}}$ is Area of the single module $\left(\mathrm{m}^{2}\right)$, and

$\mathrm{N}_{\mathrm{m}}^{\prime}$ is the corrected number of modules to the nearest integer number.

\section{Estimating the SWPS cost}

The total cost for the solar water pumping system is estimated in the present simulation program taking into account the direct cost of unit price of each component of the system like PV modules, frames, inverters, pumps, piping, and wiring. The cost includes also the indirect costs like land purchasing, land preparation, labor, taxes, and any item if applicable. A sample of the computer solar water pumping cost output sheet is illustrated in Fig.7.

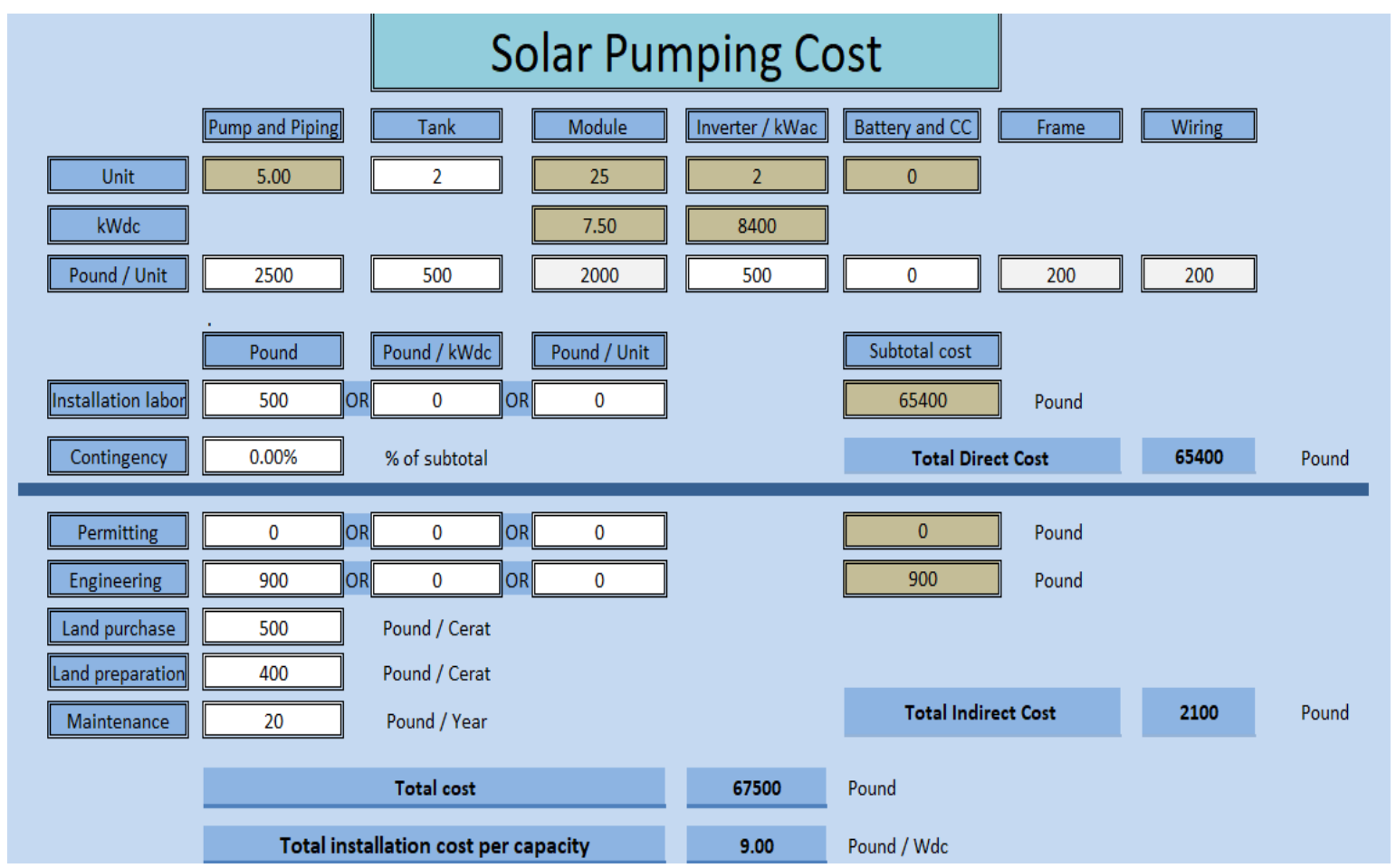

Fig. 7 Solar water pumping system cost output sheet.

\section{Results and Discussion}

Several simulation runs were conducted for the solar water pumping system. The simulated data of the daily average solar radiation for Cairo city is shown in Fig. 8. As the water demand can vary significantly for different water applications (drinking water supply, livestock watering, irrigation, industry, and any application) at different locations in Egypt, therefore six different cases of water needs are used in the simulation model with capacities of 50, 100,150, 200, 250, $300\left(\mathrm{~m}^{3} /\right.$ day) as shown in Fig. 9.

According to the average daily water demand (ranges from $50-300 \mathrm{~m}^{3} /$ day) and TDH $(50 \mathrm{~m}$ and $150 \mathrm{~m})$, the power required for pumps $(\mathrm{kW})$ can be calculated. The relation between water demand (ranged from 50 to $300 \mathrm{~m}^{3}$ /day) and pump power with different values for 
TDH $(\mathrm{m})$ is illustrated in Fig. 10. The SWPS is calculated based on the electrical power needs with specified water demands as given by Eqs. 7 and 8. The variation of PV peak power and its related area is illustrated in Figs. 11 and 12.

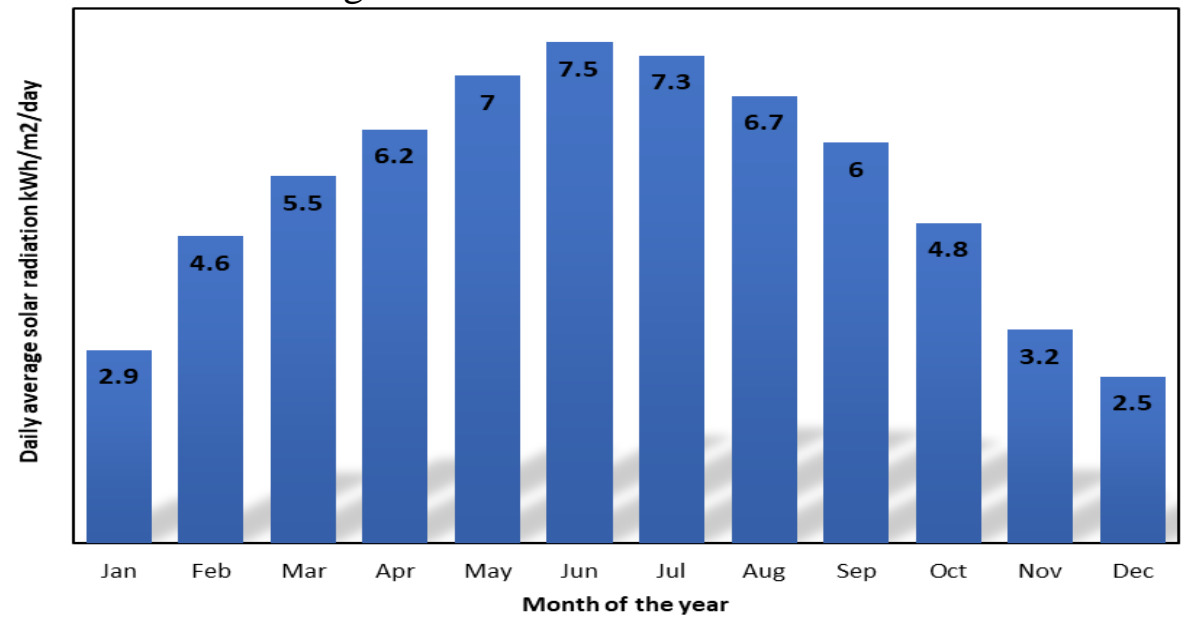

Fig. 8 Simulated data of the daily average solar radiation of Cairo city.

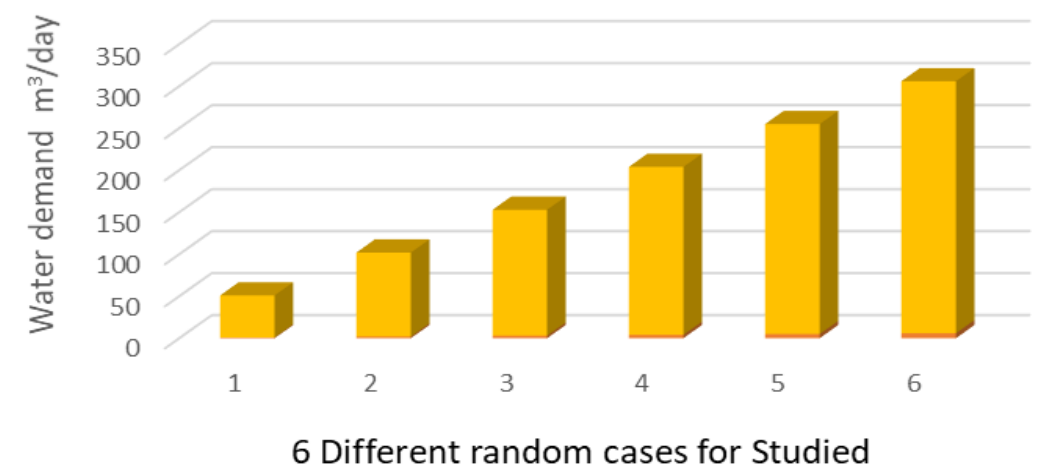

Fig. 9 Random cases for studied of water needs.

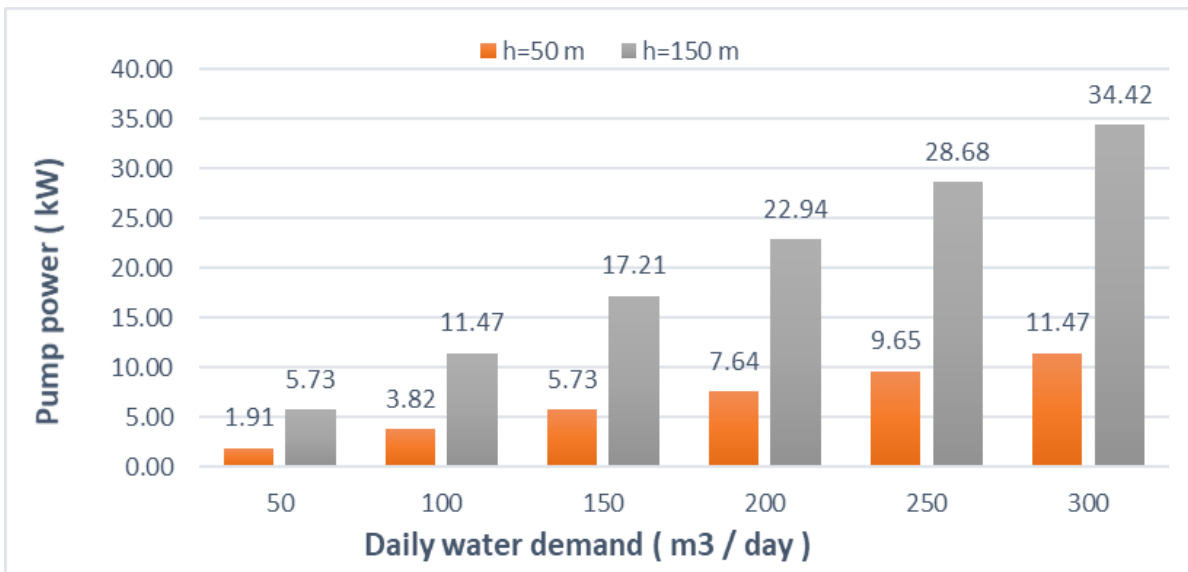

Fig. 10 Estimated pump power with different daily water demands for Cairo City. 


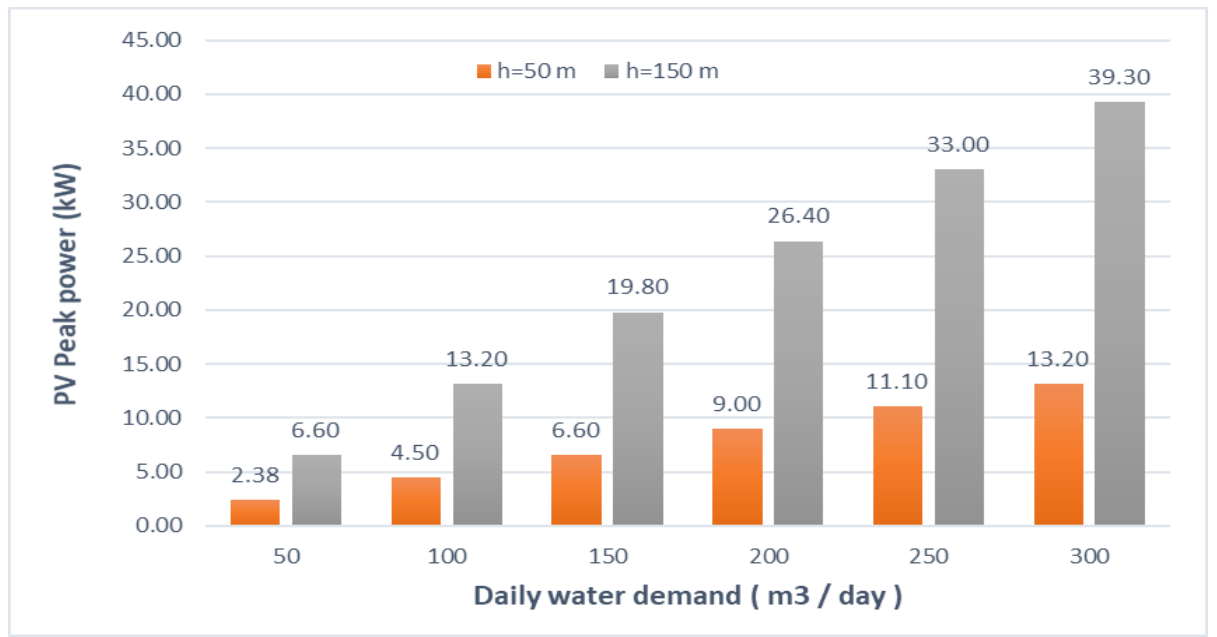

Fig. 11 Solar PV peak power variation with different daily water demands for Cairo City.

The system cost depends on several parameters, for instance manufacturing country/company, brand name (for the main components like PV panel, pumps, and inverters), PV type of technology (as an example; mono crystalline or polycrystalline silicon, thin film, etc.), taxes, customs ....etc.

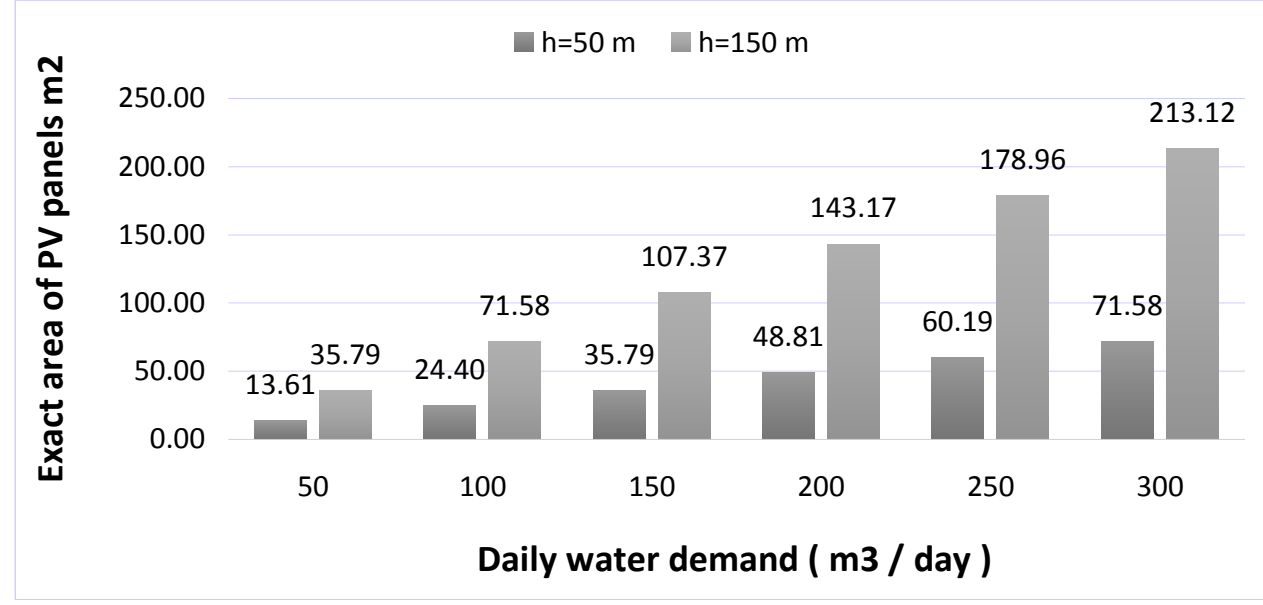

Fig. 12 Actual area of panels, $m^{2}$ with different daily water demands for Cairo City.

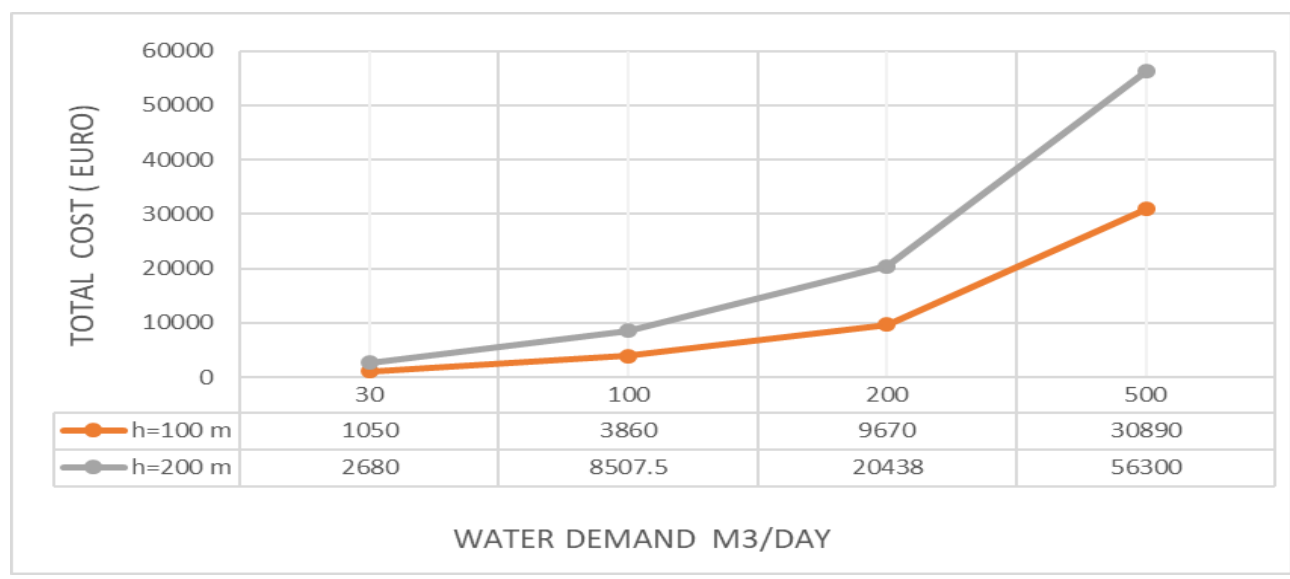

Fig. 13 Total cost with different daily water demands for Cairo city.

As a case study for Cairo city several runs of the simulation model were employed to furnish the total cost of the solar water pumping system in Euro for different water demands $\mathrm{m}^{3} / \mathrm{day}$ and different TDH. The obtained results are given in Fig. 13. 


\section{CONCLUSIONS}

Solar water pumping systems are seen to be one of the feasible solutions for use in many locations and in particular in rural and isolated remote areas where conventional power sources are unavailable or available at unaffordable cost. Solar energy is a clean source of energy, abundantly available with an average daily radiation of about $5.5 \mathrm{kWh} / \mathrm{m}^{2} /$ day. The present study presented a detailed mathematical modeling and performance evaluation for a complete design of the PV solar system components with different water demands. This is done by means of a computer program developed and designed by the authors. The program calculates accurately the hydraulic power, PV peak power, PV required area, and total system costs for different total dynamic heads and different water demands ranged from 50-300 $\mathrm{m}^{3} /$ day. The simulated results can be given for any water demand, the corresponding pump electric power at the desired total dynamic head, the required PV peak power and its related area requirements and the corresponding total cost of the system components in Euro. This program, based on its scientific merit, offers a much needed powerful accurate good tool for designers, users, and customers. The program is versatile and as such furnishes several solutions for the costumer to select according to his budget and desires.

\section{REFERENCES}

1- Hatem, M. A., 1990, National specialized board reports, Vol. 1, residential Council, The Arab Republic of Egypt, 1974-1989.

2- FAO. Aqua stat Database. FAO; 2015.

3- Darouich HM, Pedras CMG, Gonçalves JM, Pereira LS. Drip vs. surface irrigation: A comparison focusing on water saving and economic returns using multi-criteria analysis applied to cotton. Bio systems Engineering. 2014;122:74-90.

4- Mohammedi A, Mezzai N, Rekioua D, Rekioua T. Impact of shadow on the performances of a domestic photovoltaic pumping system incorporating an MPPT control: A case study in Bejaia, North Algeria. Energy Conversion and Management. 2014;84:20-9.

5- Abdalla M. Kishta, "Designing, modeling, and testing a solar water pump for developing countries" (2002). Retrospective Thesis and Dissertations. Paper 391. State University.

6- NRCS, Natural Resources Conservation Service, Design of Small Photovoltaic (PV) Solar-Powered Water Pump Systems, Technical Note No. 28, PORTLAND, OREGON, October 2010.

7- Duffie, J.A. and Beckman, W.A., Solar Engineering of Thermal Processes, 2nd Edition, John Wiley \& Sons, 1991.

8- http://www.nrcan.gc.ca/energy/software-tools/7465

9- Egyptian Organization of Standards, http://www.eos.org.eg/en

10- Henryk Kudela , "Hydraulic losses in pipes", Wroclaw University of Science and Technology $\mid$ WUT · Division of Numerical Flow Modeling, https://www.researchgate.net/publication/265535267_Hydraulic_losses_in_pipes, 2015

11- Dr. Jan Kleiss1, " Deep-well, Low-flow Photovoltaic Water Pumping system design ", Research Article, University of California, San Diego, Andres Nottrott, http://solar.ucsd.edu/nottrott/reports/Nottrott_SolarWellIrrigation.pdf

12- C. Perakis, E.T. El Shenawy, H.H. El Ghetany, G. Kyriakarakos, Design of autonomous PV/RO desalination systems case studies for Egypt and Greece.

13- Nicholle Kovach, Design of Small Photovoltaic (PV) Solar-Powered Water Pump Systems, Technical Note No. 28, PORTLAND, OREGON, , United state department of Agriculture, Natural Resources Conservation Service, October 2010

14- V. B. Shinde and S. S. Wandre, Solar photovoltaic water pumping system for irrigation: A review, African Journal of Agricultural Research, Vol.10(22), pp. 22672273 , May 2015. 


\section{NOMENCLATURES}

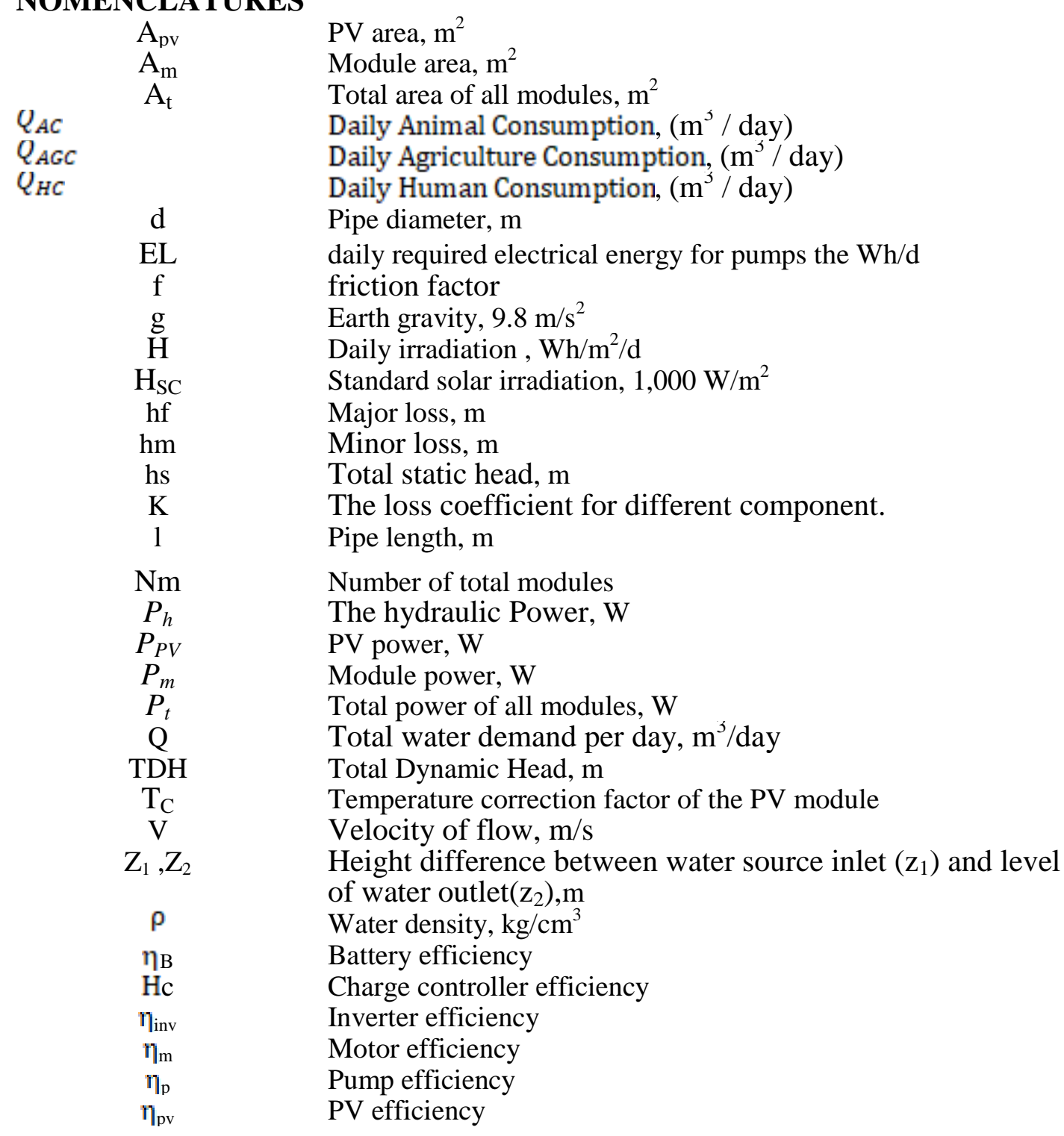

